\title{
CONGENITAL TUBERCULOSIS AND MATERNAL SARCOIDOSIS
}

\author{
BY \\ N. V. O'DONOHOE \\ From Our Lady's Hospital for Sick Children, Crumlin, Dublin
}

(RECEIVED FOR PUBLICATION OCTOBER 4, 1962)

The clinical aspects and the literature of congenital tuberculosis were well reviewed by Hudson (1956), who also described a case with survival. The case to be described is noteworthy because of the unusual features of the mother's illness.

\section{Case Report}

A female infant, aged 7 weeks, was admitted to Our Lady`s Hospital for Sick Children, Dublin, on December 30, 1961. Her birth history had been normal and she had received B.C.G. vaccination a few days after birth. She had appeared well until about four days before admission to hospital, when she developed grunting laboured respirations and was reluctant to take feeds. On admission she was quite well nourished but febrile. dyspnoeic and cyanosed. Pitting oedema of the lower limbs was present. She had marked tachycardia but no other clinical abnormality of the cardiovascular system. Diffuse crepitations were present in the lungs and also evidence of consolidation at the right base. The liver was enlarged clinically, the edge being felt three fingers' breadth below the right costal margin. A diagnosis of bronchopneumonia and possible congestive cardiac failure was made, and the infant was treated with sulphafurazole, tetracycline and digoxin initially and later with methicillin. Rapid deterioration with increasing dyspnoea took place, however, and death occurred five days after admission. Investigations revealed a normal cerebrospinal fluid, a normal electrocardiogram, a haemoglobin estimation of $13.4 \mathrm{~g} . / 100 \mathrm{ml}$. $\left(90^{\circ}\right.$ o) and a white cell count of $22,800 / \mathrm{c}$.mm. with neutrophils accounting for $\mathbf{8 0}^{\circ}$ o of the total. Pneumococci were cultured from a throat swab. No Mantoux test was done. but it was noticed that there had been very little local reaction at the sites of B.C.G. vaccination. A chest radiograph shortly after admission showed diffuse coarse mottling throughout both lung fields; the radiologist suggested a diagnosis of bronchopneumonia.

At autopsy, the lungs showed a confluent type of tuberculous pneumonia with marked caseation. Tubercle bacilli were seen on sections stained by the Ziehl-Neelsen technique. The liver showed multiple caseous areas with a moderate fibrous tissue reaction surrounding them. The lymph nodes at the hilum of the liver were caseous. Striking caseation was demonstrated in the spleen and caseous abscesses were also present in both kidneys. There was no involvement of the brain or meninges. Sections through the umbilical vein showed multiple caseous tubercles alongside the vein (see Figure), the tubercles having well-developed fibrous tissue reactions and giant-cell systems. Tubercle bacilli were seen in one such tubercle. The vein itself was obliterated.

$M$. tuberculosis grew on Lowenstein Jensen medium in three weeks from ground-up caseous tissue from the lung, liver and spleen. A guinea-pig, inoculated with this material, died with generalized tuberculosis in five weeks. A rabbit, similarly inoculated, was killed after six months and showed a caseous lesion at the site of inoculation and tubercles in the lungs. The pathologist (Dr. P. D. Holland) regarded the organism as a human strain of M. tuberculosis.

The mother of this child was aged 32 years when the child was born and she had four other normal healthy children. She was a farmer's wife. In May 1958, she had attended Mass Miniature Radiography and was recalled for a large chest film which showed bilateral hilar enlargement and mottling in both lung fields. The family history was negative as regards tuberculosis and her only symptom was a slight productive cough. Her sputum was examined on three occasions with negative results, but guinea-pig inoculation was not done. Her sedimentation rate was normal and a Mantoux test 100 T.U. was negative. She had three children at the time; two were tuberculin negative, while the third. who had had B.C.G. vaccination at birth, was tuberculin positive. Further investigation in a chest hospital was advised, but she refused it. She was therefore kept under observation by the Public Health Department of Co. Kildare. During the remainder of 1958, more radiographs were taken without showing any change in the radiological appearances, and in October 1958 a repeat Mantoux test 100 T.U. was negative.

She became pregnant in the latter part of 1958 and after an uneventful pregnancy she had a normal baby on June 1, 1959. This baby received B.C.G. vaccination at birth. In October 1959, a further chest radiograph showed unchanged appearances in the lungs and a Heaf test was negative.

In February 1960, a chest radiograph showed that the mottling was more marked in both mid-zones and. commencing in March, she was treated with isoniazid 


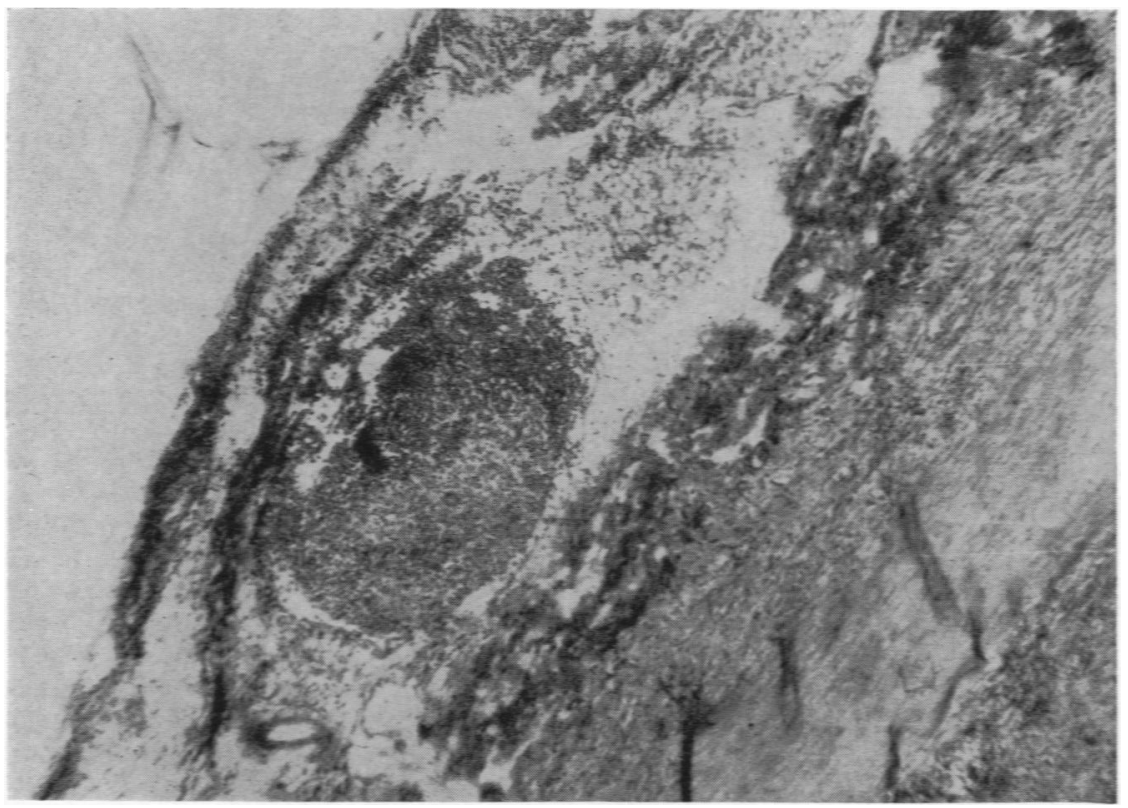

FiGURE.-The photomicrograph shows the obliterated umbilical vein on the right and a tubercke adjoining it on the left. (H. and E. $\times 100$.)

$330 \mathrm{mg}$., P.A.S. $15 \mathrm{~g}$, and prednisolone $10 \mathrm{mg}$. daily, and continued taking these drugs until April 1961.

Chest radiographs in June and September 1960 showed a definite decrease in the degree of mottling in the lungs. She became pregnant again in February 1961, and stopped taking her drugs in April because she had morning sickness. In August 1961, she had a Kveim test with material supplied by Dr. L. E. Siltzbach of Mount Sinai Hospital, New York, and the test was confirmed as being positive histologically by Dr. Siltzbach and by the Department of Pathology, University College, Dublin. At the same time her serum calcium was normal and she had a normal albumin/globulin ratio. At no time were there any other clinical manifestations of sarcoidosis, apart from the pulmonary lesions.

Following the birth of her baby in November 1961, she developed a breast abscess which was incised and coagulase positive staphylococci were cultured from the pus. This infection resolved rapidly. In December 1961, she developed an abscess in the left elbow joint region which was incised and drained pus for several months. Tubercle bacilli were cultured from this pus in the Department of Pathology, University College, Dublin. Radiological examinations of the elbow in January and April 1962, showed a localized area of bone destruction in the left olecranon. The radiologist reported that the appearances were consistent with tuberculous osteitis.

In January 1962, a further chest radiograph showed widespread miliary mottling throughout both lung fields, appearances suggestive of miliary tuberculosis. A Heaf test at this time was positive (plus 3). Treatment with streptomycin, P.A.S., and isoniazid was started, and in
March 1962 her general condition was improved, but the radiological appearances in the chest were unchanged.

\section{Discussion}

Perhaps the most acceptable view about the disputed aetiology of sarcoidosis is that it is a peculiar tissue reaction with a number of possible causes, the commonest of which is tuberculosis. Scadding (1960) prefers not to mention aetiology in defining the condition and gives the following histological definition: 'Sarcoidosis is a disease characterized by the presence in all the affected organs of epithelioid cell tubercles tending to become converted into hyalinized fibrous tissue: This allows the addition of a term indicative of aetiology where there is sufficient evidence of this aetiology, e.g. 'tuberculous sarcoidosis', or 'beryllium sarcoidosis'.

Scadding (1960) reviewed his 230 cases of sarcoidosis from the point of view of a tuberculous aetiology and found that tubercle bacilli had been isolated from $29(13 \%)$. In 18 cases, tubercle bacilli were found without the clinical course, tuberculin sensitivity, response to treatment, or prognosis deviating in any way from that observed in the rest of the series in which tubercle bacilli had not been found, and none of these had evidence of caseating tuberculosis. The tubercle bacilli were found at all stages of the disease and at various 
periods from onset. In five cases, tubercle bacilli were first found at a time of change from the clinical picture of sarcoidosis to one of caseating tuberculosis. All these cases were tuberculin-negative in the sarcoid phase and became tuberculin-positive when tubercle bacilli were found. In six cases, tubercle bacilli were isolated when the clinical picture was that of caseating tuberculosis and at varying periods before the appearance of manifestations of sarcoidosis. In five additional cases, although no documentary proof of the isolation of tubercle bacilli was available, there was an undoubted history of tuberculosis in the past. It should be mentioned that five of the tubercle bacilli isolated were typed and were found to be of human strain and of normal virulence. Scadding (1960) believes that, both in the patients in whom tubercle bacilli were found in the sarcoid phase and in those in whom there was evidence of caseating tuberculosis before or after the sarcoid phase, the entire illness was attributable to the tubercle bacilli. It is his opinion that sarcoidosis rather than caseating tuberculosis develops because of the peculiar tissue reactivity of the patient. Where tuberculosis later develops, he assumes that the reactivity of the tissues has altered. He considers it improbable that two different agents, the tubercle bacillus and an unknown agent causing sarcoidosis, might be involved in these cases.

In the case described here, there seems no doubt that the mother had sarcoidosis. Apart from the clinical and radiological features, the positive Kveim test strongly favours the diagnosis. Siltzbach (1961), an authority on the disease and on the test, contends that three out of four patients with sarcoidosis will respond with a positive test. It is interesting that the mother should have produced a normal child during the sarcoid phase of her illness. It is also of interest that transition to the tuberculous phase should have been associated with evidence of haematogenous tuberculosis rather than caseating tuberculosis. The haematogenous spread of the disease resulted in miliary lesions in her lungs, an osseous lesion in her left ulna, and probable placental involvement with resulting spread to the foetus causing congenital tuberculosis. The short history of illness in the child is a little puzzling, but it was felt on histological grounds that the tuberculous lesions around the umbilical vein and in the liver had been present for a much longer period than the lesions in the lungs and other viscera, so, presumably, generalized spread of the disease had not occurred until shortly before the child's admission to hospital.

\section{Summary}

A case of congenital tuberculosis is described in which the mother had developed haematogenous tuberculosis following pulmonary sarcoidosis. The role of $M$. tuberculosis in the aetiology of sarcoidosis is briefly discussed.

My sincere thanks are due to Dr. B. O'Donnell, County Medical Officer of Health, County Kildare, who provided me with details of the mother's illness and her $x$-ray plates, and to Dr. P. D. Holland, Pathologist to Our Lady's Hospital for Sick Children, Dublin, who was responsible for the histological and bacteriological investigation of the infant.

\section{REFERENCES}

Hudson, F. P. (1956). Clinical aspects of congenital tuberculosis. Arch. Dis. Childh., 31, 136.

Scadding. J. G. (1960). Mycobacterium tuberculosis and the aetiology of sarcoidosis. Brit med. J. 2, 1617.

Siltzbach, L. E. (1961). The Kvein test in sarcoidosis: a study of 750 patients. J. Amer. med. Ass., 178, 476. 